\title{
Premelting and the Hydrogen-Exchange Open State in Synthetic RNA Duplexes
}

\author{
R. S. PREISLER, C. MANDAL, S. W. ENGLANDER, and N. R. \\ KALLENBACH, Departments of Biology, Biochemistry and \\ Biophysics, University of Pennsylvania/G7, Philadelphia, \\ Pennsylvania 19104, and J. FRAZIER, H. T. MILES, and F. B. \\ HOWARD, Laboratory of Molecular Biology, NIMDD, National \\ Institutes of Health, Bethesda, Maryland 20205
}

\begin{abstract}
Synopsis
Here we attempt to relate equilibrium temperature-dependent spectral changes in two synthetic RNA homopolymer duplexes-poly $(\mathrm{rA}) \cdot \operatorname{poly}(\mathrm{rU})$ and poly $(\mathrm{rI}) \cdot \operatorname{poly}(\mathrm{rC})-$ to the conformational opening detected in stopped-flow hydrogen-deuterium exchange experiments on these molecules. We are concerned with changes in several spectral properties that occur well below onset of the thermally induced helix-coil "melting" transition in these systems. These are known as "premelting" transitions, and can be detected in uv CD spectra as well as in vibrational bands of the bases in the ir. Both $\mathrm{CD}$ and ir spectra exhibit isoelliptic or isosbestic points consistent with a well-defined two-state premelting process. Application of a least-squares analysis to two-state models for premelting using data from different bands in the $\mathrm{CD}$ and ir shows that the enthalpies are substantially greater than that of the hydrogen-exchange opening. Thus the hydrogen-exchange open state represents only one premelting reaction among several that lead to equilibrium changes in helix geometry or base vibrational modes. The latter include processes that occur on a rapid time scale, including potential base-pair openings not productive for the exchange reaction. It appears that the former, and not the hydrogen-exchange opening, dominates the premelting alterations monitored by ir and CD spectroscopy.
\end{abstract}

\section{INTRODUCTION}

An understanding of the structural dynamics of nucleic acids at physiological temperatures and solution conditions is likely to be important in terms of the mechanisms of fundamental cellular events, such as DNA replication, recombination, or transcription. Over a number of years, the highly cooperative helix-coil transitions seen in DNA and synthetic polynucleotides ${ }^{1}$ gave rise to a picture of the double helix as a static structure, which changes its conformation to a randomcoil form only in the vicinity of the denaturation midpoint, $T_{m}$. This notion is at variance with several lines of experimental evidence in dicating (1) that the double-helix backbone exhibits a range of large amplitude motions down to a time scale of nanoseconds, ${ }^{2}$ and (2) that a number of physical and chemical properties of DNA and polynu- 
cleotide duplexes change with temperature far below the onset of any detectable denaturation. These latter phenomena have been referred to as "premelting transitions"3 to distinguish them from melting or global helix denaturation. Premelting changes in polarographic behavior, ${ }^{4} \mathrm{CD},{ }^{5-11}$ Raman spectra, ${ }^{12-14}$ and ${ }^{31} \mathrm{P}-\mathrm{nm} \mathrm{r}$ line shapes and chemical shifts, ${ }^{2}$ have all been reported. The phenomenon in deoxypolynucleotides has been discussed in terms of gradual changes in helix parameters (winding angle or base twist ${ }^{15}$ ) without significant disruption of the double-stranded structure. As we show here, this description does not seem appropriate to the large-enthalpy premelting process in synthetic RNA duplexes studied here and in a previous publication. ${ }^{16}$

We have shown that hydrogen-exchange (HX) measurements on poly $(\mathrm{rA}) \cdot \operatorname{poly}(\mathrm{rU})$ provide evidence for the existence of an open state in this duplex in which $5 \%$ of the base pairs are broken at $\mathrm{pH} 7$ and room temperature. ${ }^{17}$ We have argued elsewhere that this opening does not lead to unstacking or internal "melting" (i.e., forming a small bubble) within the helix. Instead, what we refer to as the HX open state appears to involve a minimal torsional oscillation of the duplex that severs both $\mathrm{H}$ bonds in either poly $(\mathrm{rA}) \cdot \operatorname{poly}(\mathrm{rU})$ or poly $(\mathrm{rI}) \cdot \operatorname{poly}(\mathrm{rC})$ without loss of most of the stacking free energy. The extent of opening is lower in the latter helix ( $1 \%$ at room temperature), but poly $(\mathrm{rI}) \cdot \operatorname{poly}(\mathrm{rC})$ behaves similarly to $\operatorname{poly}(\mathrm{rA}) \cdot \operatorname{poly}(\mathrm{rU})$ in other respects. (We refer to these homopolymer complexes here as "AU" and "IC," respectively.)

Given that a number of features of the polynucleotide duplex can be seen to depend on temperature in premelting, is this a manifestation of the same opening responsible for exposing base-pair protons to exchange? In order to answer this question, we have carried out an extended series of equilibrium spectroscopic measurements on the AU and IC duplexes over a temperature range of about $50^{\circ} \mathrm{C}$ below the $T_{m}$. We use CD to provide a probe of helix geometry as well as base-pairing present, since the interactions responsible are sensitive to both properties. $^{5-11}$ We use ir spectroscopy because, while it is relatively insensitive to base stacking in single-stranded polynucleotides, it is extremely sensitive to changes in conformation in hydrogen-bonded nucleic acids. ${ }^{18}$ If premelting in these duplexes involves the kind of changes postulated for DNA, the CD and ir spectra might be expected to reveal distinctive thermal transition profiles. On the other hand, the ir measurement seems more likely to reflect conformational effects corresponding to the base-pair breaking required in HX opening. This work extends our preliminary observations reported previously. ${ }^{16}$

\section{THEORY}

We attempt here to compare the temperature dependence of the ir and $C D$ spectra of $A \cdot U$ and $I \cdot C$ duplexes with that determined from 
the HX rates, measured on the same samples, over the same range of temperatures (where possible). To answer the question raised above, or evaluate the hypotheses just considered, requires quantitative comparison of these properties. Consider a minimal two-state transition model

$$
\mathrm{A} \rightleftharpoons \mathrm{B}
$$

for which $K_{\mathrm{eq}}$ denotes the equilibrium constant, and let $\alpha$ be a parameter responsive to the difference between $A$ and $B$. Then at temperature, $T$

$$
\ln K_{\mathrm{eq}}=\ln \left(\frac{\alpha_{\mathrm{A}}-\alpha}{\alpha-\alpha_{\mathrm{B}}}\right)=\frac{\Delta S^{0}}{R}-\frac{\Delta H^{0}}{R T}
$$

Here, $\alpha_{A}$ and $\alpha_{B}$ are the values of the intensity or frequency of a spectral band (for example) which describe a set of molecules entirely in the A or B state. $\Delta H^{0}$ and $\Delta S^{0}$ are the van't Hoff enthalpy and entropy, respectively, for the transition. ${ }^{19}$ Our objective is to try to determine $K_{\text {eq }}$ from sets of temperature-dependent CD or ir spectral data, and to relate these to the analogous results from HX kinetics.

Determining the temperature dependence of the equilibrium constant is straightforward from the hydrogen exchange. ${ }^{17}$ The model for opening-dependent hydrogen exchange is

$$
H_{\text {closed }} \rightleftharpoons H_{\text {open }} \rightarrow H_{\text {exchanged }}
$$

where a proton cannot exchange in the native duplex (or closed) state, but can exchange following a conformational change to an open state. The reference states $\mathrm{A}$ and $\mathrm{B}$, for closed and open base pairs, respectively, are experimentally observable or theoretically definable. Thus, $K_{\text {eq }}$ can be computed from the first equality in Eq. (1). Measuring $K_{\text {eq }}$ at several temperatures leads to the van't Hoff enthalpy $\Delta H^{\circ}$.

The calculation of enthalpies for spectroscopically measured premelting is, by comparison, problematical. Since we do not now what sort of conformational change is detected by ir or $\mathrm{CD}$, we are unable to define "nonpremelted" and "fully premelted" reference states or predict their spectral properties. In terms of Eq. (1), we do not know $\alpha_{A}$ and $\alpha_{B}$.

In order to calculate values of $K_{\mathrm{eq}}$ and $\Delta H^{0}$ from spectroscopic data, we first tried a least-squares computer-fitting scheme (Program I) based on the method of Powell et al. ${ }^{19}$ The program is given a range of guesses of $\Delta H^{0}$ and $T_{m}=\Delta H^{0} / \Delta S^{0}$. From each pair of these parameters, it calculates values of the equilibrium constant and fits values of $\alpha_{\mathrm{A}}$ and $\alpha_{\mathrm{B}}$ to provide trial values of the spectroscopic values, 
$\alpha_{i}^{*}$, to be compared with the experimental values, $\alpha_{i}$ at each temperature, $T_{i}$. The combination of $\Delta H^{0}$ and $T_{m}$ values that minimize the sum

$$
S=\sum_{i}\left(\alpha_{i}^{*}-\alpha_{i}\right)^{2}
$$

is selected.

For most of our spectroscopic data sets, the program failed to find a minimum over a wide range of $\Delta H^{0}$ and $T_{m}$ values. Therefore, we modified the program to include a normalizing assumption. ${ }^{16}$ The values of $K_{\text {eq }}$ at $20^{\circ} \mathrm{C}$ were arbitrarily set to the equilibrium constant derived from $\mathrm{HX}$ kinetic data for that temperature, 0.05 for $\mathrm{AU}$ and 0.01 for IC. With this constraint, the $T_{m}$ becomes a function of $\Delta H^{0}$ and enthalpy values are the only input. The modified program (II) found minima for a larger number, but still not all, of the spectroscopic data sets.

Those spectroscopically derived enthalpies of which we are reasonably confident lie predominantly in a range from two to three times the values from the HX-rate experiments. Thus, if ir is measuring the same open state as HX, the former technique must also be detecting substantial additional conformational changes which do not affect exchange rates. The kinds of premelting effects that have been invoked to explain CD spectral changes in DNA should have a smaller enthalpy than base-pair opening, provided that units of equal size are involved in each case. The fact that in RNA the CD premelting enthalpies are larger than those from HX indicates either a larger transition "unit" or a process different from the one suggested for DNA.

\section{MATERIALS AND METHODS}

Polyadenylic [poly(rA)], polyuridylic [poly(rU)], polyinosinic [poly$(\mathrm{rI})]$, and polycytidylic [poly $(\mathrm{rC})]$ acids were purchased from P-L Biochemicals. Solutions of individual polymers were extensively dialyzed to remove small contaminating fragments. Polymer sizes were determined by electrophoresis on $8 M$ urea, $10 \%$ acrylamide gels to be larger than 100 nucleotides. Concentrations were determined by uv absorption in a Perkin-Elmer 552 spectrophotometer. The following molar extinction values $\left(\boldsymbol{M}^{-1 / \mathrm{cm}}\right)$ were used: poly $(\mathrm{rA}), 10,400$ at $257 \mathrm{~nm}$; poly $(\mathrm{rU}), 9900$ at $260 \mathrm{~nm}$; poly(rI), 10,260 at $248 \mathrm{~nm}$; and poly(rC), 6300 at $268 \mathrm{~nm} .{ }^{20,21}$ The $1: 1$ complexes, AU and IC, were prepared by mixing the polymer solutions in the mass ratios that gave equimolarity. Each mixture was heated to denaturing temperature and allowed to cool slowly to ensure complete renaturation.

Kinetic properties of base-pair opening reactions were measured in an OLIS stopped-flow spectrophotometer system equipped with a Bausch and Lomb monochromator and an observation cell, photomultiplier, and mixing system from Durrum. The instrument was in- 
terfaced to a NOVA2 computer, using OLIS software. Each polynucleotide complex in $\mathrm{D}_{2} \mathrm{O}$ solution was mixed with nine volumes of $\mathrm{H}_{2} \mathrm{O}$ buffer, and the resulting small decrease in optical density around $290 \mathrm{~nm}$ (arising from a red shift in the kinetic difference spectrum) was monitored on as many as three different time scales. ${ }^{17}$

Infrared spectra in $\mathrm{D}_{2} \mathrm{O}$ were measured in 26 - or $54-\mu \mathrm{m} \mathrm{CaF}{ }_{2}$ cells in a Perkin-Elmer 580B spectrophotometer, with temperature regulated by a circulating water bath. $\mathrm{CD}$ spectra in $\mathrm{H}_{2} \mathrm{O}$ were recorded, using $1 \mathrm{~cm}$ quartz cuvets, with a Jasco J500A spectrometer, regulated with a Lauda bath. Both ir and CD instruments were interfaced to Dec 1103 computers which transmitted data to a Honeywell 516 at NIAMDD for processing. Programs I and II were run on the PDP-10 computer system at the University of Pennsylvania School of Medicine.

\section{RESULTS}

\section{Kinetics of Hydrogen-Deuterium Exchange}

A time-dependent uv spectral shift is produced by exchanging deuterons on the base chromophores of $\mathrm{AU}$ and IC with solvent protons. The time course of this process, monitored at the peaks of the respective H-D kinetic difference spectra ( $290 \mathrm{~nm}$ for AU; $293 \mathrm{~nm}$ for IC) can be analyzed according to two first-order processes. Figure 1 shows Arrhenius plots for the fast and slow rates observed with both complexes, measured between 10 and $40^{\circ} \mathrm{C}$ in $\mathrm{AU}$ and between 15 and $35^{\circ} \mathrm{C}$ in IC.

Detailed studies of hydrogen-deuterium exchange (HX) in AU and its component monomers and polynucleotides ${ }^{17}$ allow the fast reaction to be assigned to the uracil $\mathrm{N}-3$ imino proton and the slow reaction to the two exocyclic amino protons of adenine (Fig. 2). Although only one of the two amino protons is involved in interbase hydrogen bonding while the other is exposed to the solvent, they exchange at the same rate. Because of the high basicity of the amino group in the unmodified base, the exchange process near neutral $\mathrm{pH}$ proceeds via prior protonation of the adenine ring $\mathrm{N}-1$, which is also hydrogen bonded in the duplex. Finally, the uracil imino proton participates in WatsonCrick base pairing as well, and is buried in the double helix. These observations lead to the conclusion that exchange of the three protons with solvent requires base-pair breakage or opening.

The imino proton of uracil exchanges by a direct transfer to solvent $\mathrm{OH}^{-}$more rapidly than the reclosing of the base pair. Since this reaction accompanies every base-pair breakage, the rate of the fast phase is equivalent to the rate of helix opening. Thus, according to the data plotted in Figure 1, AU opens with a rate constant of $1.1 \mathrm{~s}^{-1}\left(t_{1 / 2}=\right.$ $630 \mathrm{~ms})$ at $20^{\circ} \mathrm{C}$.

The adenine amino protons exchange through a preequilibrium 

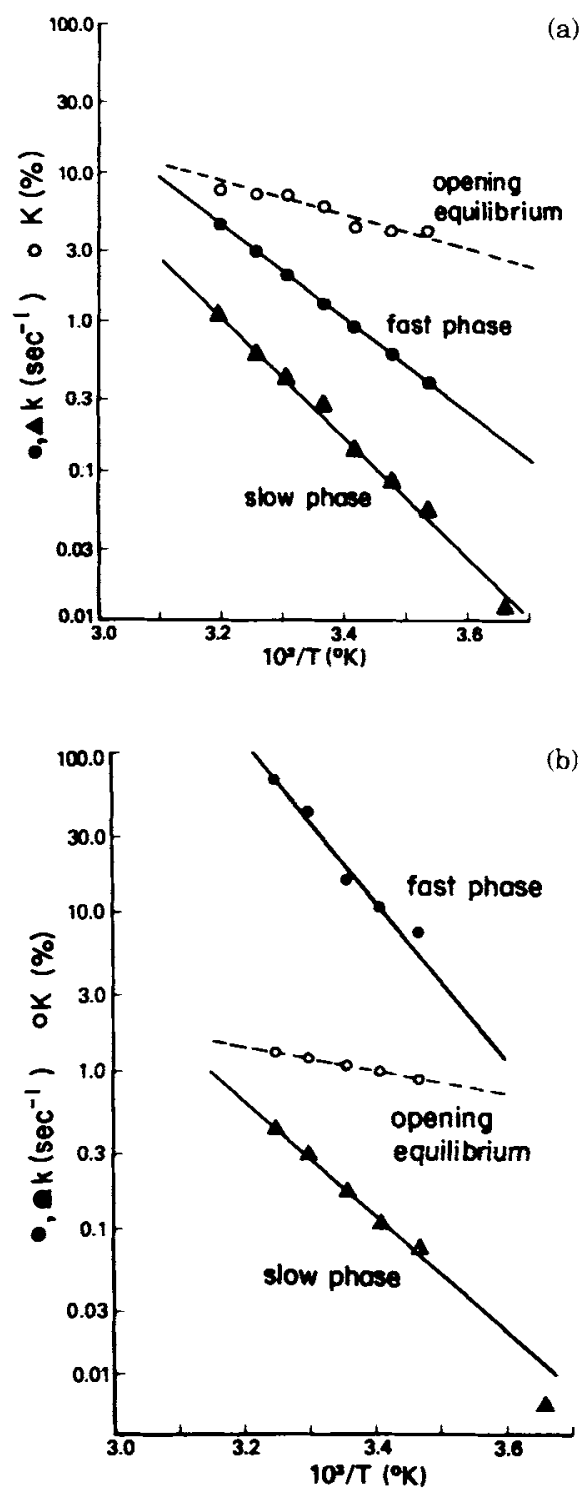

Fig. 1. Temperature-dependence of hydrogen-exchange kinetics and the base-pairopening equilibrium: (a) poly(rA) - poly $(\mathrm{rU})$; (b) poly $(\mathrm{rI}) \cdot$ poly $(\mathrm{rC})$. Kinetic data were obtained in $100 \mathrm{mM} \mathrm{NaCl}, 10 \mathrm{mM} \mathrm{NaH} \mathrm{PO}_{4}, \mathrm{pH} 7.0$, with a computer-interfaced stoppedflow spectrophotometric system. Rate constants for exchange, $k_{\mathrm{ex}}$, are represented in an Arrhenius plot of in $k_{\text {ex }}$ vs $1 / T$. Opening equilibrium constant, $K_{\text {op }}$, was calculated as described in Results. These data are represented in a van't Hoff plot of In $K_{\text {op }}$ vs $1 / T$. 


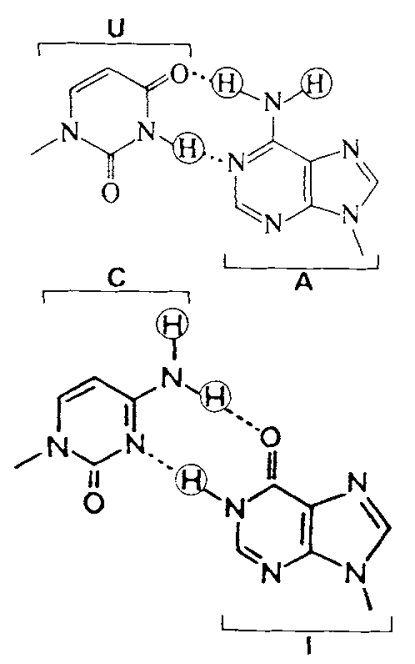

Fig. 2. Exchangeable protons in A:U and I:C base pairs. Exchange of the circled hydrogens with solvent is detected with the stopped-flow spectrophotometric technique.

mechanism from the transiently open base pair. This process is sensitive to $\mathrm{pH}$ and general base catalysis under the same conditions affecting exchange of the amino protons in single-stranded poly $(\mathrm{rA})$ or monomer AMP. Either of these component moieties of AU can be used to represent the $100 \%$ open reference state. Poly $(\mathrm{rA})$, which is considerably stacked at room temperature, is the appropriate choice if the open state is assumed to retain stacking of the adenine base with its nearest neighbors (as in the minimal model presented in Ref. 17). AMP, on the other hand, would be a better reference for a model in which the open state involves unstacking of the adenine.

Although a different expression has been derived from the specific model for open-limited hydrogen exchange, ${ }^{17} \mathrm{Eq}$. (1) can be applied to determining the equilibrium constant for base pair opening, $K_{\text {op }}$. In this example, the observed parameters are the temperature-dependent exchange rate constants $k_{\mathrm{ex}}$ of the slow phase (amino exchange) in AU. State A is the theoretical fully closed helix, where the rate constant for amino exchange, is zero. Using kinetic data from $20^{\circ} \mathrm{C}$ and poly(rA) for state $B$, we calculate

$$
\begin{aligned}
K_{\mathrm{op}} & =\frac{\alpha_{\mathrm{A}}-\alpha}{a-\alpha_{\mathrm{B}}}=\frac{k_{\mathrm{ex}}(\text { closed })-k_{\mathrm{ex}}(\mathrm{AU})}{k_{\mathrm{ex}}(\mathrm{AU})-k_{\mathrm{ex}}[\mathrm{poly}(\mathrm{rA})]} \\
& =\frac{(0.0-0.14) \mathrm{s}^{-1}}{(0.14-3.1) \mathrm{s}^{-1}}=0.05
\end{aligned}
$$

The result with AMP as the fully open standard is given in Table I.

We have recently performed a similar investigation of $\mathrm{HX}$ in IC, 
TABLE I

Kinetic and Thermodynamic Parameters of Hydrogen Exchange and Base-Pair Opening ${ }^{a}$

\begin{tabular}{|c|c|c|}
\hline Property & $\operatorname{Poly}(r A): P o l y(r U)$ & $\operatorname{Poly}(r \mathrm{l}): \operatorname{Poly}(\mathrm{rC})$ \\
\hline$k_{\text {ex }}$ (fast phase) $\left(\mathrm{s}^{-1}\right.$ at $20^{\circ} \mathrm{C}$ ) & 1.1 & 12 \\
\hline$k_{\text {ex }}$ (slow phase) $\left(\mathrm{s}^{-1}\right.$ at $\left.20^{\circ} \mathrm{C}\right)$ & 0.14 & 0.13 \\
\hline \multicolumn{3}{|l|}{ Polynucleotide Standard } \\
\hline$K_{\text {op }}\left(\right.$ at $\left.20^{\circ} \mathrm{C}\right)$ & 0.05 & 0.01 \\
\hline$\Delta H^{0}(\mathrm{kcal} / \mathrm{mol})$ & 3.8 & 3.7 \\
\hline$\Delta S^{0}(\mathrm{cal} / \mathrm{mol} \mathrm{K})$ & 6.7 & 3.3 \\
\hline$T_{m}\left({ }^{\circ} \mathrm{C}\right)$ & 290 & 840 \\
\hline \multicolumn{3}{|l|}{ Mononucleotide Standard } \\
\hline$K_{\text {op }}\left(\right.$ at $\left.20^{\circ} \mathrm{C}\right)$ & 0.02 & 0.004 \\
\hline$\Delta H^{0}(\mathrm{kcal} / \mathrm{mol})$ & 6.1 & 6.3 \\
\hline$\Delta S^{0}(\mathrm{cal} / \mathrm{mol} \mathrm{K})$ & 12 & 2.5 \\
\hline$T_{m}\left({ }^{\circ} \mathrm{C}\right)$ & 240 & 360 \\
\hline
\end{tabular}

${ }^{a}$ Kinetic measurements were performed in $100 \mathrm{mM} \mathrm{NaCl}, 10 \mathrm{mM} \mathrm{NaH} \mathrm{PO}_{4}$, pH 7.0.

details of which will be published elsewhere. We conclude that the fast reaction (Fig. 1) corresponds to exchange of the N-1 imino proton in hypoxanthine and the slow process involves the two exocyclic C-4 amino protons of cytosine (Fig. 2). As in AU, two out of three exchangeable protons participate in base pairing in the duplex, implying that exchange is dependent on opening. Nakanishi and Tsuboi ${ }^{22}$ have reported similar exchange rates in IC. They originally assigned the fast reaction to the nonhydrogen-bonded cytosine amino proton and the slow reaction to the hypoxanthine imino and hydrogen-bonded cytosine amino protons. This interpretation is inconsistent with the $\mathrm{HX}$ behavior of component monomers and polymers, ${ }^{17}$ as well as with our data on the $\mathrm{pH}$ dependence of exchange in IC, and has since been retracted.

The hypoxanthine imino proton exchanges in a direct, conformationally dependent manner analogous to the uracil imino proton in

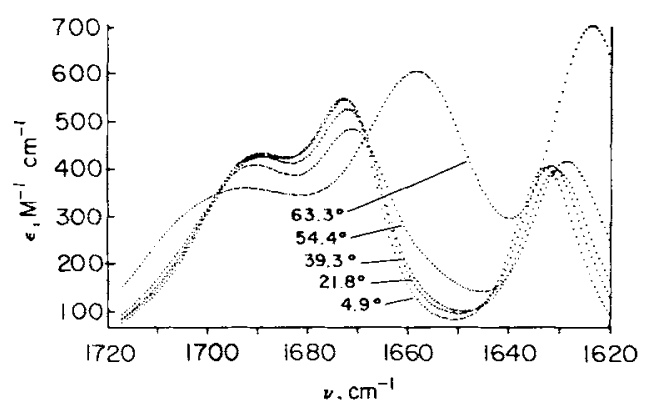

Fig. 3. Infrared spectra of poly $(\mathrm{rA})$ :poly $(\mathrm{rU})$ at different temperatures. Solvent was $\mathrm{D}_{2} \mathrm{O}, 100 \mathrm{mM} \mathrm{NaH} \mathrm{PO}_{4}$, pD 7. Data are corrected for a slight drift in baseline (between 1800 and $1750 \mathrm{~cm}^{-1}$ ) with temperature. 


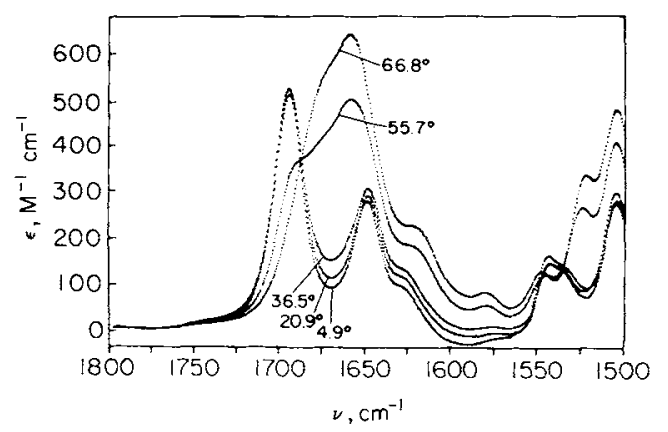

Fig. 4. Infrared spectra of poly $(r \mathrm{l}): p o l y(r \mathrm{C})$ at different temperatures. Conditions and corrections were the same as those described in the legend to Fig. 3.

AU. Thus, the rate constant for the fast phase in IC measures the opening of the helix, which occurs at $12 \mathrm{~s}^{-1}\left(t_{1 / 2}=58 \mathrm{~ms}\right)$ at $20^{\circ} \mathrm{C}$ (Fig. 1). The cytosine amino protons exchange via the same sort of preequilibrium opening-dependent mechanism, with prior protonation at $\mathrm{N}-3$ in cytosine, as was previously described for the adenine protons in AU. Thus, $K_{\text {op }}$ for IC can be calculated from the rate constant of the slow phase, with reference either to poly $(\mathrm{rC})$ or $\mathrm{CMP}$. The results are listed in Table I.

Van't Hoff plots (ln $K_{\text {op }}$ vs $1 / T$ ) for base-pair opening in AU and IC are included in Figure 1. In the form

$$
\ln K_{\mathrm{eq}}=-\left(\Delta H^{0} / R\right)(1 / T)+\Delta S^{0} / R
$$

the enthalpy can be calculated from the slope and entropy from the $y$ intercept of these graphs.

At $T=T_{m}$, the two states involved in the transition are at equal concentration, and $K_{\text {eq }}=1$. Thus from Eq. (4)

TABLE II

Assignments of IR Absorption Bands ${ }^{\mathrm{a}}$

\begin{tabular}{|c|c|c|c|c|c|}
\hline \multicolumn{3}{|c|}{ Poly(rA):Poly $(r U)$} & \multicolumn{3}{|c|}{$\operatorname{Poly}(r \mathrm{I}): \operatorname{Poly}(\mathrm{rC})$} \\
\hline $5^{\circ} \mathrm{C}$ & $70^{\circ} \mathrm{C}$ & Assignment & $5^{\circ} \mathrm{C}$ & $70^{\circ} \mathrm{C}$ & Assignment \\
\hline \multicolumn{6}{|c|}{ Frequency $\left(\mathrm{cm}^{-1}\right)$} \\
\hline 1569 & 1576 & A-ring & 1505 & 1505 & C-ring (I-ring) ${ }^{b}$ \\
\hline 1633 & 1624 & A-ring & 1543 & 1522 & C-ring (I-ring) ${ }^{\mathrm{b}}$ \\
\hline 1673 & 1658 & U-C4 carbonyl & 1648 & 1659 & C-carbonyl \\
\hline 1689 & 1692 & U-C2 carbonyl & 1695 & & I-carbonyl \\
\hline
\end{tabular}

Spectra were measured in $\mathrm{D}_{2} \mathrm{O}, 100 \mathrm{mM} \mathrm{NaCl}, 1 \mathrm{mM} \mathrm{NaH} \mathrm{PO}_{4}$, pD 7. Assignments are based on information in Refs. 18 and 23.

b Smaller contributions in parentheses. 


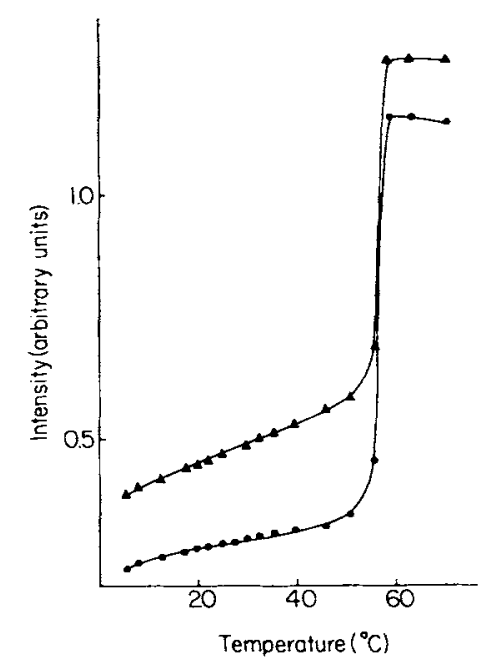

Fig. 5. Intensities of vibrational bands in poly(rA):poly $(\mathrm{rU})$ as a function of temperature: (†) $1658.5 \mathrm{~cm}^{-1}$, (A) $1624.0 \mathrm{~cm}^{-1}$. Baseline-corrected data. $T_{m}$ for the helix-coil transition was estimated to be $57^{\circ} \mathrm{C}$ from the data at both frequencies. This value is in close agreement with the $T_{m}$ determined from uv spectroscopy (Ref. 24).

$$
\Delta H^{0} / R T_{m}=\Delta S^{0} / R \text { or } T_{m}=\Delta H^{0} / \Delta S^{0}
$$

Values of enthalpy, entropy, and $T_{m}$ for base-pair opening in AU and IC are given in Table I.

\section{Premelting Changes in the IR and CD Spectra}

Infrared spectra of $\mathrm{AU}$ and $\mathrm{IC}$ in $\mathrm{D}_{2} \mathrm{O}, 0.1 \mathrm{M} \mathrm{NaCl}$, were measured at 18 different temperatures between 5 and $70^{\circ} \mathrm{C}$. Selected spectra are plotted in Figures 3 and 4 and band assignments are given in Table II. Obvious premelting changes can be seen in both intensities (Figs. 5 and 6 ) and frequency (Fig. 7) of the vibrational bands in each complex. Isosbestic points for spectra covering the entire range of temperatures occur at 1698,1668 , and $1562 \mathrm{~cm}^{-1}$ in $\mathrm{AU}$, and at 1688,1548 , and 1536 $\mathrm{cm}^{-1}$ in IC. It is interesting to note that additional isosbestics are shared only by spectra in the premelting region. These occur at 1687 , 1646,1631 , and $1571 \mathrm{~cm}^{-1}$ in $\mathrm{AU}$, and at 1703,1675 , and $1514 \mathrm{~cm}^{-1}$ IC.

The $\mathrm{CD}$ of $\mathrm{AU}$ and IC was measured at 21 different temperatures between 2 and $72^{\circ} \mathrm{C}$. Selected spectra are plotted in Figures 8 and 9 . Many bands of both synthetic RNAs exhibit significant premelting shifts in intensity and wavelength. The intensity changes at three different wavelengths are illustrated in Figure 10. In AU, there are isoelliptics shared only by premelting spectra (256 and $288 \mathrm{~nm}$ ) or only by melting spectra $(255 \mathrm{~nm})$. The full range of AU spectra exhibit 


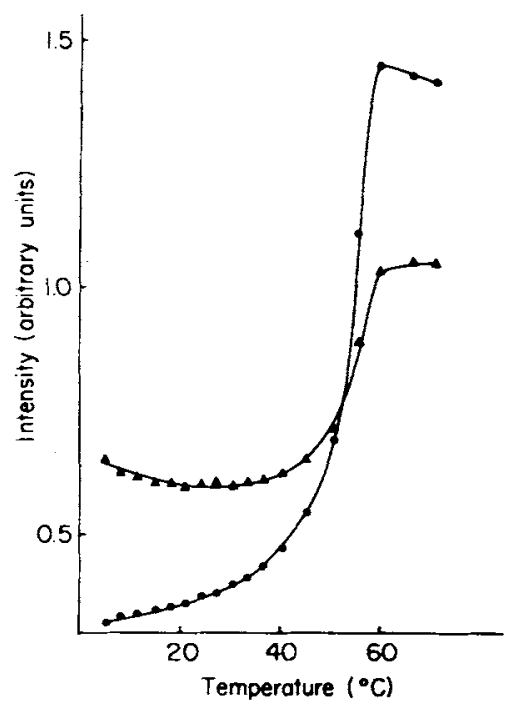

Fig. 6. Intensities of vibrational bands in poly $(\mathrm{rI})$ :poly $(\mathrm{rC})$ as a function of temperature: (C) $1659.0 \mathrm{~cm}^{-1}$, (A) $1505.0 \mathrm{~cm}^{-1}$. Baseline-corrected data. Estimated $T_{m}$ from both sets of data is $55^{\circ} \mathrm{C}$, as compared to a range of values between 55 and $61^{\circ} \mathrm{C}$ from uv spectroscopy (Ref. 24).

common isoelliptics at 217,238 , and $296 \mathrm{~nm}$. In IC, isosbestic points occur at 219 (premelting only), 265 (melting only), and 256 and 269 $\mathrm{nm}$ (all temperatures).

\section{Determination of Thermodynamic Parameters from Spectroscopic Premelting Data}

Table III describes the sets of ir and CD data that were analyzed with programs I and II. These include intensities $(I)$ and frequencies $(v)$ of vibrational bands and $\mathrm{CD}$ in molar extinction units $(\epsilon)$ at different temperatures. Difference spectra for ir (Fig. 11) and CD (Fig. 12) were calculated by subtracting the spectrum at the lowest temperature of observation from each of the remaining spectra. The intensity $(\Delta I)$ of some of the ir difference bands and the differential $\mathrm{CD}(\Delta \Delta \epsilon)$ of some bands were analyzed with the two programs. In all cases, data were selected from each temperature observed, from the lowest to about $45^{\circ} \mathrm{C}$, a point well below the first manifestation of the cooperative helixcoil transition.

Program I was given a wide latitude of guesses for fitting each data set: $\Delta H^{\circ}$ between 1.0 and $50 \mathrm{kcal} / \mathrm{mol}$ and $T_{m}$ between -100 and $2000^{\circ} \mathrm{C}$. The value $50 \mathrm{kcal} / \mathrm{mol}$ was considered a reasonable upper limit because the apparent enthalpy for a highly cooperative transition such as melting is itself in the hundreds of $\mathrm{kcal} / \mathrm{mol} ; 2000^{\circ} \mathrm{C}$ was chosen because it is several times larger than the $T_{m}$ values calculated from 


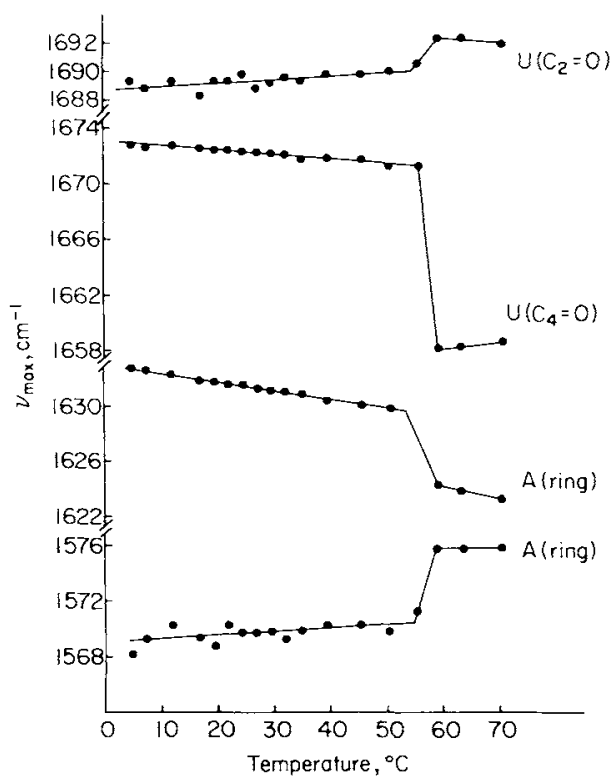

Fig. 7. Frequencies of vibrational bands in poly $(\mathrm{rA})$ :poly $(\mathrm{rU})$ as a function of temperature. Baseline-corrected data.

HX data (Table I). If the program selected a pair of values within these extremes, it was rerun using successively narrower ranges of guesses, until the minimizing value of $\Delta H^{0}$ was determined to the nearest 100 $\mathrm{cal} / \mathrm{mol}$ and $T_{m}$ to two significant figures. These results are listed in Table IV. On the other hand, no further iterations were attempted if the first run selected values at one or more of the extreme guesses; for example, $\Delta H^{0}=1.0 \mathrm{kcal} / \mathrm{mol}$ or $T_{m}=2000^{\circ} \mathrm{C}$. In these cases, Eq. (3) is minimized by enthalpy or $T_{m}$ values outside our "reasonable" range. This sort of result is indicated with the appropriate "greater than" or "less than" signs in Table IV.

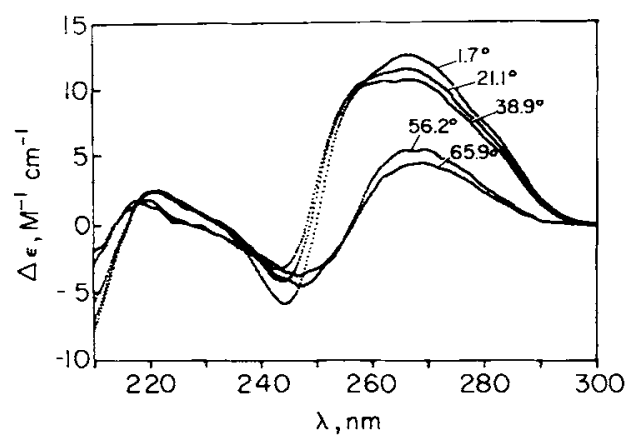

Fig. 8. $\mathrm{CD}$ of poly(rA):poly(rU) at different temperatures. The solvent was $\mathrm{H}_{2} \mathrm{O}, 100$ $\mathrm{m} M \mathrm{NaCl}, 1 \mathrm{~m} M \mathrm{NaH}_{2} \mathrm{PO}_{4}, \mathrm{pH}$ 7.0. Data were corrected for a slight drift in baseline (over $300 \mathrm{~nm}$ ) with temperature. 


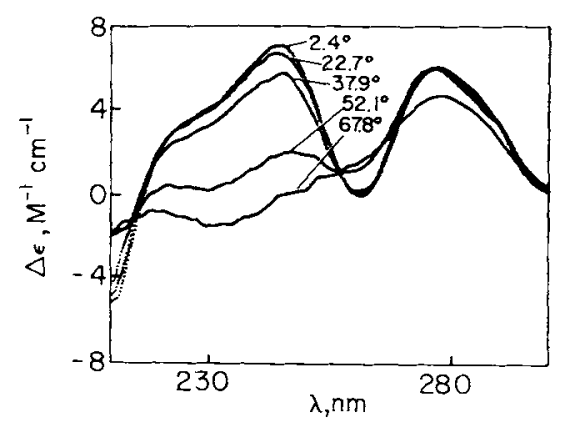

Fig. 9. $\mathrm{CD}$ of poly $(\mathrm{rl})$ :poly(rC) at different temperatures. Conditions and corrections were the same as those described in the legend to Fig. 8.

According to the above criteria, program I produced a successful minimization with only about one-third of the data sets. The analysis of the $K_{\mathrm{op}}$ data from $\mathrm{HX}$ (sets 1 and 16) generated enthalpies in close agreement with the values we had calculated from van't Hoff plots (Table I), especially for IC. However, the minimizing value for $T_{m}$ was over $2000^{\circ} \mathrm{C}$.

Program II (see Introduction) incorporates an additional normalizing assumption, specifying a value of $K=K_{\text {ref }}$ at $T=T_{\text {ref }}$. Equation (4) becomes

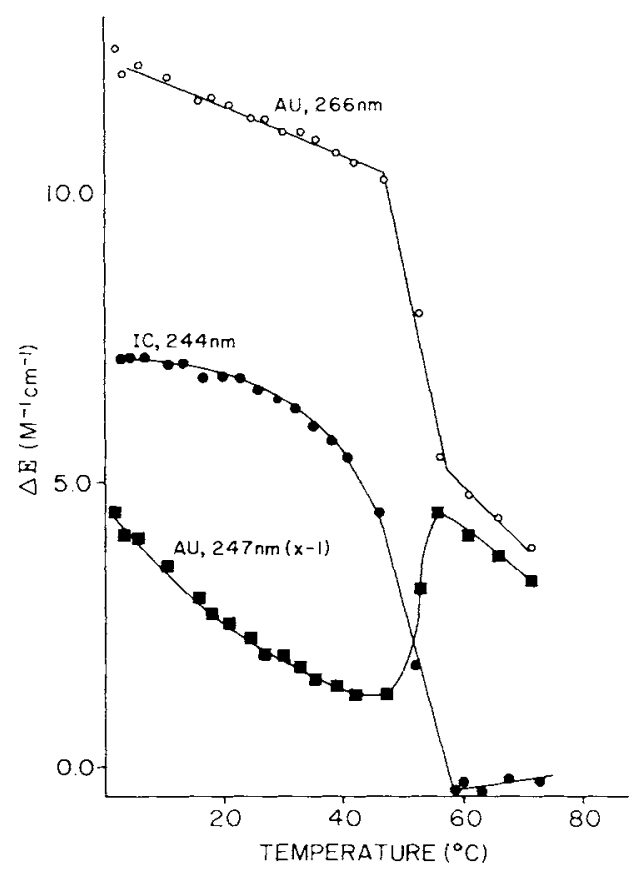

Fig. 10. Intensities of $\mathrm{CD}$ bands as a function of temperature. Baseline-corrected data. 
TABLE III

Description of Data Sets

\begin{tabular}{|c|c|c|c|c|}
\hline & Set Number & Technique & Parameter & $\begin{array}{l}\text { Frequency }\left(\mathrm{cm}^{-1}\right) \text { for } \\
\text { IR, or Wavelength } \\
\text { (nnn) for CD }\end{array}$ \\
\hline \multirow[t]{15}{*}{$\operatorname{Poly}(\mathrm{rA}): \operatorname{poly}(\mathrm{rU})$} & 1 & $\mathrm{HX}$ & $K_{\mathrm{op}}{ }^{\mathrm{a}}$ & \\
\hline & 2 & ir & I & 1690 \\
\hline & 3 & ir & I & 1672 \\
\hline & 4 & ir & I & 1658 \\
\hline & 5 & ir & I & 1624 \\
\hline & 6 & ir & I & 1663 \\
\hline & 7 & ir & I & 1624 \\
\hline & 8 & ir & & 1690 \\
\hline & 9 & ir & & 1672 \\
\hline & 10 & ir & & 1631 \\
\hline & 11 & ir & & 1570 \\
\hline & 12 & $\mathrm{CD}$ & & 244 \\
\hline & 13 & $\mathrm{CD}$ & & 266 \\
\hline & 14 & $\mathrm{CD}$ & & 247 \\
\hline & 15 & $\mathrm{CD}$ & & 266 \\
\hline \multirow[t]{9}{*}{ Poly(rI):poly(rC) } & 16 & $\mathrm{HX}$ & $K_{\mathrm{op}}^{\mathrm{b}}$ & \\
\hline & 17 & ir & I & 1694 \\
\hline & 18 & ir & 1 & 1659 \\
\hline & 19 & it & I & 1648 \\
\hline & 20 & ir & I & 1505 \\
\hline & 21 & ir & I & 1698 \\
\hline & 22 & ir & I & 1530 \\
\hline & 23 & $\mathrm{CD}$ & & 244 \\
\hline & 24 & CD & & 246 \\
\hline
\end{tabular}

a Poly(rA) standard.

${ }^{b}$ Poly $(\mathrm{rC})$ standard.

$$
\ln K_{\mathrm{ref}}=a / R=-\Delta H^{0} / R T_{\mathrm{ref}}+\Delta S^{0} / R
$$

where $a$ is a constant. Solving for $\Delta S^{0}$ gives

$$
\Delta S^{0}=\left(1 / T_{\text {ref }} \Delta H^{0}\right)-a=b\left(\Delta H^{0}\right)-a
$$

where $b$ is another constant; $\Delta S^{0}$ is now a function of $\Delta H^{0}$. Thus, only guesses of the enthalpy, again between 1.0 and $50 \mathrm{kcal} / \mathrm{mol}$, were given. The results of fitting the data sets with program II are listed in Table IV. About two-thirds of the sets, including the $\mathrm{HX} K_{\mathrm{op}}$ data, were successfully fit.

\section{DISCUSSION}

\section{Evaluation of Data-Fitting Routines}

The analytical methods used to derive thermodynamic parameters from premelting data are based on the assumption of a transition 

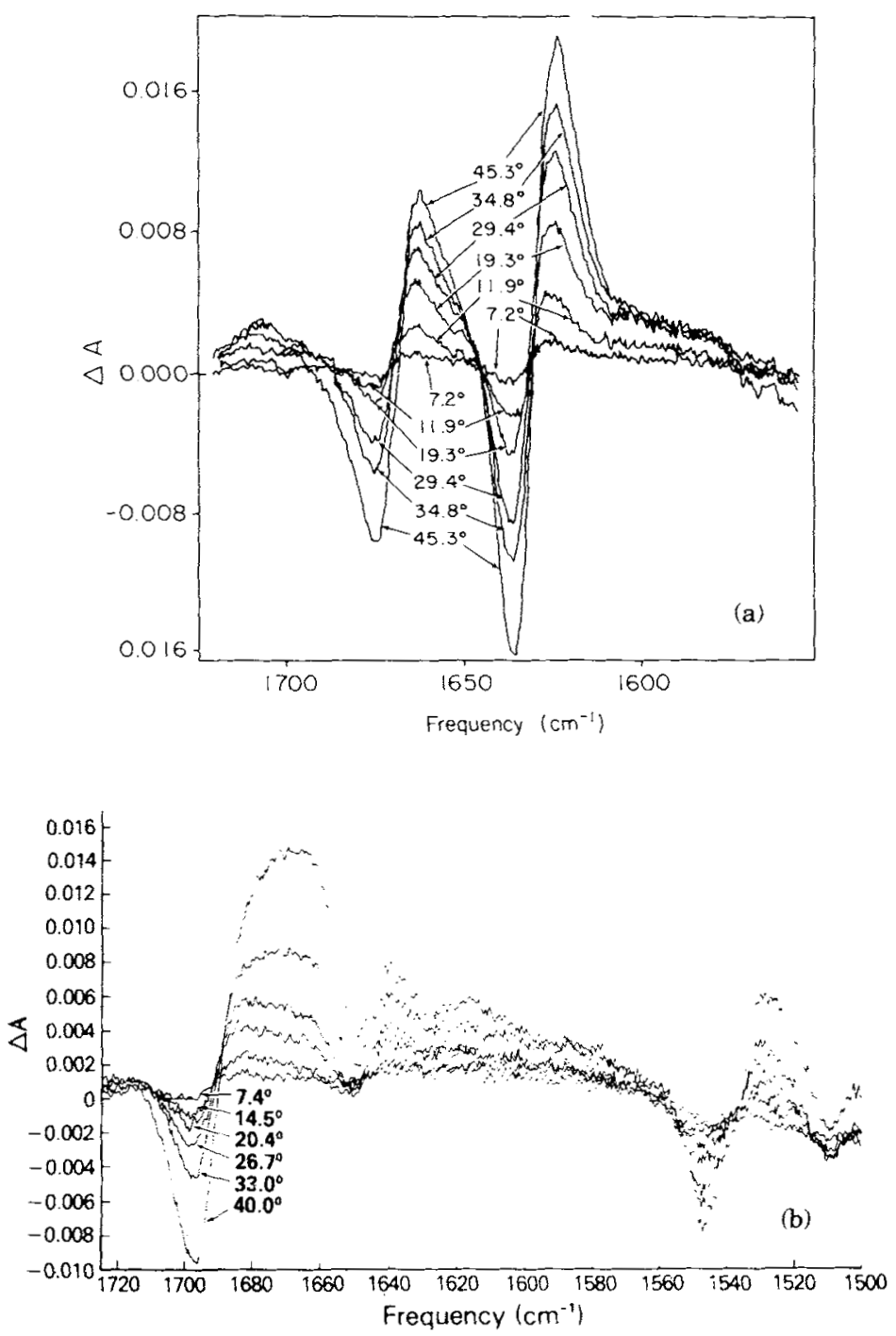

Fig. 11. Infrared temperature-difference spectra: (a) $\operatorname{poly}(\mathrm{rA}) \cdot \operatorname{poly}(\mathrm{r} \mathrm{U})$, (b) poly(rI) - poly $(\mathrm{rC})$. For each synthetic $\mathrm{RNA}$, the lowest temperature spectrum was subtracted from each of the other spectra in the premelting range.

between two discrete states. This model is useful in describing the effect of temperature on $\mathrm{HX}$ kinetics where the two states represent a base pair unavailable for exchange and an open base pair. Powell and her co-workers ${ }^{19}$ found originally that the temperature-dependent conformational change in dinucleoside phosphates, as monitored by CE or uv absorption, could also be treated as a transition between two states fully stacked and unstacked.

In attempting to analyze the ir and CD premelting data, however, 


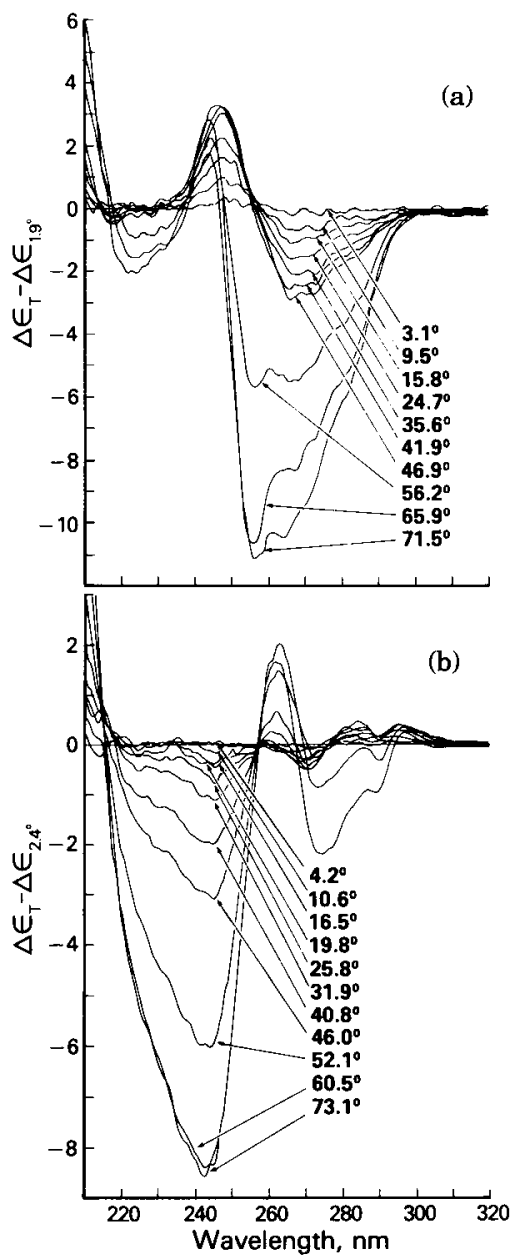

Fig. 12. CD temperature-difference spectra: (a) poly(rA):poly(rU), (b) poly(rI):poly(rC). Procedure was the same as that described for Fig. 11.

we are hindered by the lack of obvious reference states for defining a conformational transition. One reason is that we are uncertain of the nature of the changes detected by spectroscopy, although various possibilities will be explored later in this discussion. Second, whatever "premelting" is, the low-temperature point at which the double helices are totally "nonpremelted" is not known. Davis and his co-workers" measured the CD of DNA in high concentrations of $\mathrm{LiCl}$, allowing them to collect spectra at temperatures down to $-50^{\circ} \mathrm{C}$. They observed that the decrease in amplitude of the long-wavelength positive band leveled off at about $-35^{\circ} \mathrm{C}$. It appears unlikely that the data from the lowest temperatures in our series, $2^{\circ} \mathrm{C}$ for $\mathrm{CD}$ and $5^{\circ} \mathrm{C}$ for ir, are close to the lower end of the premelting transition. At higher temperatures, the noncooperative transition is obscured by the highly cooperative 
TABLE IV

Results of Computer-Fitting Routines

\begin{tabular}{|c|c|c|c|c|}
\hline \multirow{2}{*}{$\begin{array}{c}\text { Set } \\
\text { Number }\end{array}$} & \multicolumn{2}{|c|}{ Program I } & \multicolumn{2}{|c|}{ Program II } \\
\hline & $H^{0}(\mathrm{kcal} / \mathrm{mol})$ & $T_{m}\left({ }^{\circ} \mathrm{C}\right)$ & $H^{0}(\mathrm{kcal} / \mathrm{mol})$ & $T_{m}\left({ }^{\circ} \mathrm{C}\right)$ \\
\hline 1 & 5.5 & $>2000$ & 6.0 & 150 \\
\hline 2 & 50 & 170 & 34 & 41 \\
\hline 3 & 16 & 52 & 14 & 69 \\
\hline 4 & 2.0 & -100 & 1.0 & -100 \\
\hline 5 & 25 & 49 & 26 & 47 \\
\hline 6 & 2.6 & -100 & 1.0 & -100 \\
\hline 7 & 1.0 & -100 & 1.0 & 100 \\
\hline 8 & 22 & 39 & 13 & 74 \\
\hline 9 & 17 & 27 & 1.6 & -100 \\
\hline 10 & 1.8 & 2000 & 1.7 & -100 \\
\hline 11 & 9.4 & 2000 & 9.6 & 93 \\
\hline 12 & 9.4 & 11 & 1.0 & -100 \\
\hline 13 & 2.3 & 2000 & 2.2 & 2000 \\
\hline 14 & 6.3 & -13 & 1.0 & -100 \\
\hline 15 & 1.0 & 2000 & 1.0 & -100 \\
\hline 16 & 4.3 & 2000 & 4.4 & 510 \\
\hline 17 & 39 & 44 & 29 & 56 \\
\hline 18 & 14 & 2000 & 14 & 96 \\
\hline 19 & 8.9 & 2000 & 9.1 & 150 \\
\hline 20 & 50 & 37 & 46 & 44 \\
\hline 21 & 17 & 2000 & 18 & 79 \\
\hline 22 & 7.0 & 2000 & 7.3 & 200 \\
\hline 23 & 14 & 2000 & 14 & 95 \\
\hline 24 & 14 & 2000 & 14 & 96 \\
\hline
\end{tabular}

process of denaturation. Although the $T_{m}$ for the helix-coil transition in $\mathrm{Au}$ and $\mathrm{IC}$ is in the range of $55-60^{\circ} \mathrm{C}$, the $\mathrm{HX}$ measurements between 10 and $40^{\circ} \mathrm{C}$ extrapolate to apparent $T_{m}$ values between 200 and $900^{\circ} \mathrm{C}$ for localized base-pair openings (Table I). A number of spectroscopic data sets also yield $T_{m}$ values greater than denaturing temperatures (Table IV), although we consider these to be less reliable than the $H^{0}$ values, as will be discussed later. It cannot be assumed that the "fully premelted" molecules have the same conformation or spectrum as the random coil. Hence we cannot use the latter as a reference state for the premelting transition.

Program I computes values of the spectral parameters, $\alpha_{A}$ and $\alpha_{B}$ [Eq. (1)], corresponding to the pure states, A and B, at the two endpoints of the transition. A van't Hoff line is calculated for each of the combinations of input guesses of $\Delta H^{0}$ and $T_{m}$. Each van't Hoff equation generates values of the spectroscopic parameter; $\alpha^{*} T$, for each of the observation temperatures. The $\alpha_{T}$ values are compared to the experimental $\alpha_{T}$ until the combination of guesses producing the minimum sum of squares [Eq. (3)] is identified.

The minimization procedure may fail or generate anomalous results 
if the experimental data deviate greatly from the form of a van't Hoff line. Such a problem could arise if (1) the parameter, $\alpha$, is not sufficiently temperature-dependent, ${ }^{19}(2)$ the data are excessively noisy, (3) the data represent a transition among more than two states or more than one transition, or (4) the transition is cooperative. To some extent, the last alternative is refuted by the gradual nature of the apparent spectral changes over a broad temperature range. However, a residual weak cooperativity cannot be excluded. The third possibility cannot be addressed because of our limited understanding of premelting. The first two alternatives are difficult to assess by inspection of the experimental data because in the course of the fitting routine, the data are transformed into coordinates of $\ln K$ and $1 / T$ via operations dependent on unknown values of $\Delta H^{0}$ and $T_{m}$. Some of the data sets that seemed to be noisy were successfully fit by program I; some of the "cleanest" sets, such as the intensities at $1624 \mathrm{~cm}^{-1}$ in the ir spectrum of AU (Fig. 5; data set 5 in Table IV) were not.

In program II, $\Delta S^{0}$ (and $T_{m}$ ) becomes a function of $\Delta H^{0}$ [Eq. (7)], meaning that the $y$-intercept of a van't Hoff line is determined by its slope. Consequently, the range of possible fits to a data set is greatly reduced. Since the $20^{\circ} \mathrm{C}$ point is fixed at a low value of $K_{\text {eq }}(0.05$ for $\mathrm{AU}$ and 0.01 for $\mathrm{IC}$ ), and the experimental temperatures are clustered closely around $20^{\circ} \mathrm{C}$ (especially in the $1 / T$ transform), the likelihood of minimization by outlandish values of $\Delta H^{0}$ (and $T_{m}$, a function of $\Delta H^{0}$ ) is diminished. Nevertheless, the failure of program II with one-third of the data sets suggests that this scheme is still sensitive to large deviations from ideal behavior by the experimental points.

The imposition of values of $K_{\text {eq }}$ derived from HX on spectroscopic data is, of course, arbitrary and raises questions about the validity of these fits. However, examination of Table IV reveals a striking correlation between enthalpies generated by programs I and II. In a number of cases, applying the normalizing assumption brings $T_{m}$ inside our limits without significantly affecting $\Delta H^{0}$. Because of the wide discrepancies between $T_{m}$ values produced by the two programs, and the dependence of $T_{m}$ on $\Delta H^{0}$ in program II, we do not place much weight on interpretation of $T_{m}$ (or $\Delta S^{0}$ ) figures. Enthalpies generated by program I were selected for further consideration if they fulfilled one of the following criteria: (1) the values for a data set derived from programs I and II were similar to within $10 \%$ and the $T_{m}$ derived from either program was within the assigned limits, and/or (2) both $\Delta H^{0}$ and $T_{m}$ values derived from program I were within the assigned limits. These enthalpy data of reasonable confidence are listed in Table V.

\section{Premelting and Melting Transitions}

A number of observations and theoretical considerations suggest that the premelting reported here and in the literature is distinct from the helix-coil transition. 
TABLE V

Calculated Enthalpies of Premelting Transitions

\begin{tabular}{|c|c|c|c|}
\hline & Technique & Number of data sets & $H^{0}(\mathrm{kcal} / \mathrm{mol})$ \\
\hline $\operatorname{Poly}(\mathrm{rA}): \operatorname{poly}(\mathrm{rU})$ & $\mathrm{HX}$ & 1 & $\begin{array}{l}3.8^{\mathrm{a}} \\
6.1^{\mathrm{b}} \\
5.5^{\mathrm{c}}\end{array}$ \\
\hline & $\mathrm{CD}$ & 5 & $\begin{array}{c}16 \\
25 \\
22 \\
17 \\
9.4 \\
\text { (Average) } 18 \pm 5.4 \\
9.4 \\
6.3 \\
\text { (Average) } 7.9\end{array}$ \\
\hline $\operatorname{Poly}(\mathrm{rI})$ poly(rC) & $\mathrm{HX}$ & 1 & $\begin{array}{l}3.7^{\mathrm{a}} \\
6.3^{\mathrm{a}} \\
4.3^{\mathrm{c}}\end{array}$ \\
\hline & $\mathrm{CD}$ & 5 & $\begin{array}{c}39 \\
14 \\
8.9 \\
17 \\
7.0 \\
\text { (Average) } 17 \pm 11 \\
14 \\
14 \\
\text { (Average) } 14\end{array}$ \\
\hline
\end{tabular}

${ }^{3}$ From van't Hoff plot based on Eq. (1); polynucleotide standard.

${ }^{b}$ From van't Hoff plot based on Eq. (1); mononucleotide standard.

' From program I; polynucleotide standard.

Ultraviolet hyperchromicity is considered to be a sensitive monitor of double-helix denaturation. Our measurements (data not shown), in agreement with previous work, ${ }^{21,25}$ show essentially no uv absorbance change until five degrees below the $T_{m}$, or over $50^{\circ} \mathrm{C}$, in both $\mathrm{AU}$ and IC. Temperature effects on HX kinetics as well as in ir and CD spectral bands are, of course, prominent at much lower temperatures.

Denaturation is a highly cooperative transition with an apparent enthalpy change in the range of hundreds of $\mathrm{kcal} / \mathrm{mol}$. Premelting, on the other hand, is characterized by $\Delta H^{0}$ values between about 5 and $20 \mathrm{kcal} / \mathrm{mol}$, depending on the technique of measurement (Table V). The cooperative unit for the CD-detected premelting of poly[d(AT)] appears to be less than 10 base pairs. ${ }^{\text {? }}$

In DNA and poly[d(A--T)] the long-wavelength positive $\mathrm{CD}$ band increases in the premelting region but decreases through the melt, ${ }^{5-7,9}$ consistent with the occurrence of a distinct process over the 
lower range of temperatures. A similar reversal is seen in the shortwavelength negative $\mathrm{CD}$ band in AU (Figs. 8 and 10).

Existence of an isosbestic point is a necessary but not sufficient condition for a transition between two conformations, ${ }^{18}$ such as helix and coil. The existence of isosbestics in the ir and CD spectra of AU and $\mathrm{IC}$ that are unique to premelting spectra is thus consistent with the hypothesis that a transition between intermediate conformations occurs prior to the onset of denaturation.

The helix-coil transition in polynucleotide duplexes is sensitive to monovalent cation concentration; the $T_{m}$ of $\mathrm{AU}$ increases by $36^{\circ} \mathrm{C}$, for example, when $\mathrm{Na}^{+}$is raised from 0.01 to $1 M$. However, the same change in $\mathrm{Na}^{+}$has no effect on the kinetics or equilibrium of basepair opening, as detected by $\mathrm{HX} .^{17}$ Another measure of premelting change, the increase in the long-wavelength $\mathrm{CD}$ band in DNA and poly[d(A-T)], also is insensitive to a 100 -fold increase in $\mathrm{Na}^{+} .^{7}$

Gralla and Crothers ${ }^{26}$ estimated a probability of $10^{-10}$ for concerted opening of nine $\mathrm{A}: \mathrm{U}$ base pairs in a long RNA double helix at $25^{\circ} \mathrm{C}$. In their model, the $A: U$ region is bounded by $G: C$ pairs. Thus, the probability should be slightly higher in AU. However, formation of an analogous denatured bubble in IC should be considerably less likely. In contrast to these predictions, we observed from $\mathrm{HX}$ that 0.05 of the base pairs in $\mathrm{AU}$ and 0.01 in IC are open at $25^{\circ} \mathrm{C}$. The relatively high frequency of observed openings at this temperature must be accounted for by localized opening of the helical structure, rather than by cooperative denaturation of such a large proportion of the duplex. The fraction of base pairs involved in spectroscopically observed premelting changes is extremely difficult to determine absolutely with any precision. But the fact that both IR and CD can detect these phenomena implies that they also must be far more probable than denatured bubbles.

\section{Interpretation of Premelting Changes in IR and Raman Spectra}

No previous studies of premelting using ir absorption spectroscopy have been published, but several workers have reported low-temperature changes with Raman scattering. ${ }^{12-14}$ Although the selection rules for ir and Raman transitions are different, the two techniques produce a number of similar bands in large asymmetric molecules such as polynucleotides. Small and Peticolas ${ }^{12}$ found, in the Raman spectrum of $\mathrm{AU}$ in $\mathrm{D}_{2} \mathrm{O}$, uracil carbonyl and adenine ring vibration bands at frequencies close to the corresponding ir bands. Upon melting, a Raman band appears at $1660 \mathrm{~cm}^{-1}$ analogous to the uracil $\mathrm{C} 4$ carbonyl band at $1658.5 \mathrm{~cm}^{-1}$ in the ir. In both cases, there is a premelting increase in intensity, much smaller in magnitude but in the same 
direction as the melting hyperchromism. Because of the sensitivity of the uracil carbonyl bands to hydrogen bonding, ${ }^{18}$ their premelting change in the Raman band is ascribed to a gradual "loosening" of the native hydrogen-bonded structure..$^{2}$ On the other hand, the frequency shift of the uracil carbonyl band in the ir (Fig. 7), which parallels strikingly the behavior of a thymine carbonyl Raman band in DNA, ${ }^{13}$ implies that unstacking of bases, as well as hydrogen-bond breakage, may account for premelting in this spectral region.

Small and Peticolas ${ }^{12}$ do not indicate whether the adenine ring vibration band at $1623-1631 \mathrm{~cm}^{-1}$ in the Raman spectrum of AU shows premelting effects. However, they present data for the ring vibration bands at 1236 (uracil) and $730 \mathrm{~cm}^{-1}$ (adenine), in $\mathrm{H}_{2} \mathrm{O}$ solvent. Both bands increase with temperature, consistent with base unstacking. In the ir spectrum, there are analogous hyperchromic premelting and melting changes at $1624 \mathrm{~cm}^{-1}$ (adenine ring vibration, Fig. 5). Unstacking here is accompanied by a large blue shift (Fig. 7), as is also observed in the uracil Raman band $\left(1238 \mathrm{~cm}^{-1}\right)$.

Parallel premelting changes are seen in the ir spectrum of IC. The hypoxanthine and cytosine carbonyl vibrations occur, respectively, at 1695 and $1648 \mathrm{~cm}^{-1}$ in the low-temperature spectrum (Fig. 4 and Table II). These shift either to the red (hypoxanthine) or the blue (cytosine), forming, in the denatured spectrum, a broad band with a peak at 1659 $\mathrm{cm}^{-1}$, and an asymmetric profile leaning toward higher frequencies (wave numbers). This band is a summation of the poly $(\mathrm{rI})\left(1673 \mathrm{~cm}^{-1}\right)$ and poly $(\mathrm{rC})\left(1656 \mathrm{~cm}^{-1}\right)$ vibrations. ${ }^{27}$ The low-temperature band at $1543 \mathrm{~cm}^{-1}$ includes contributions from both hypoxanthine and cytosine ring vibrations, with the latter predominating. As the bases unstack, this band shifts to the red $\left(1522 \mathrm{~cm}^{-1}\right.$ in the denatured spectrum) and increases in intensity. The band at $1505 \mathrm{~cm}^{-1}$ also is a combination of a large cytosine band [1504.5 $\mathrm{cm}^{-1}$ in poly $\left.(\mathrm{rC})\right]$ and a smaller hypoxanthine band $\left[1507 \mathrm{~cm}^{-1}\right.$ in poly(rI) $] .{ }^{27}$ Perhaps because of its complexity, this band displays the unusual behavior of a decrease in intensity in the premelting region followed by hyperchromism during the melt (Fig. 6). Its frequency does not change over the entire temperature range of observation.

The Raman band at $814 \mathrm{~cm}^{-1}$ in $\mathrm{AU}\left(\mathrm{H}_{2} \mathrm{O}\right.$ solvent) has been assigned to the symmetric stretching of the phosphodiester group. ${ }^{12}$ Its intensity decreases over a wide range of temperatures, implying a gradual loss of the native ordered structure of the backbone during the premelt followed by an abrupt cooperative transition to the random coil.

\section{Interpretation of Premelting Changes in CD Spectra}

There have been a number of reports demonstrating premelting changes in the CD spectra of DNA and synthetic deoxyribopolymer 
duplexes..$^{5-11}$ The intensity of the long-wavelength positive band (around $278 \mathrm{~nm}$ in DNA and $262 \mathrm{~nm}$ in poly[d(A--T)]) increases with temperature in the premelting region, but decreases upon denaturation. The negative band at about $247 \mathrm{~nm}$ increases through both premelting and melting. Davis and his co-workers found that reducing the ionic strength at a constant temperature produced the same effects on the $\mathrm{CD}$ as did raising the temperature in the premelting region. ${ }^{11}$ Experiments with closed circular superhelical $\mathrm{DNA}^{28}$ showed that either of these environmental changes decreases the winding angle of the double helix. Consequently, several authors have attributed the premelting $\mathrm{CD}$ effects to a reduction in the helix winding angle $(\sigma$ or $\tau$ ), or equivalently, to an increase in the number of base pairs per turn.

Among the major DNA structures characterized by $x$-ray diffraction, winding-angle decrease has been observed to follow the order C $>B$ $>$ A. ${ }^{15}$ Brahms and his co-workers compared their premelting spectra of poly $[(\mathrm{A}-\mathrm{T})]$ in $\mathrm{Na}^{+}$solution to a $\mathrm{Li}^{+}$film spectrum at $82 \%$ relative humidity, conditions in which ir dichroism indicated the C-helix. ${ }^{5} \mathrm{By}$ extrapolation of CD intensity measurements, they calculated that a $100 \% \mathrm{C}$ spectrum would occur in $\mathrm{Na}^{+}$solution at $-80^{\circ} \mathrm{C}$. Thus, they interpreted premelting as the transition from the $\mathrm{C}$ - to $\mathrm{B}$-form, a view shared by Greve et al. ${ }^{8}$ Gennis and Cantor ${ }^{7}$ argue against this conclusion on the grounds that DNA is more hydrated at lower temperatures, whereas the C-helix is associated with partial dehydration. Recent fiber-diffraction studies ${ }^{29}$ have demonstrated that DNA occurs in the B-form even at the highest salt concentrations (and presumably at the lowest temperatures) employed by authors of previous studies. The Cform is observed under certain drastic conditions that produce dehydration, but is unlikely to be involved in the premelting transition normally observed.

Gennis and Cantor ${ }^{7}$ regard a B-A-helix transition as an even lesslikely explanation of $\mathrm{CD}$ premelting than the $\mathrm{B}-\mathrm{C}$ conversion. The former process is expected to show a higher enthalpy than their estimate of $5 \mathrm{kcal} / \mathrm{mol}$ or less. They also predict a dependence on ionic strength for $\Delta H^{0} \mathrm{~B}-\mathrm{A}$, but observe no effect of $\mathrm{Na}^{+}$concentration. Finally, glucosylated $\mathrm{T} 2 \mathrm{r}^{+}$phage DNA, which cannot assume the Aform (at least not in films), exhibits premelting. A last piece of evidence against a B-A transition comes from Raman spectroscopy of DNA solutions. ${ }^{13}$

Johnson et al. ${ }^{15}$ found that the CD intensity at $275 \mathrm{~nm}$ was sensitive not only to variations in winding angle, but also to the tilt of the base pairs from the helix axis, the twist of the bases, the displacement of the base pairs from the helix axis, and the step height; that is, all the parameters needed for a unique assignment of the bases' relative positions. In this study, the CD spectrum was calculated for 68 different conformations of an 11-base-pair DNA, including structures deduced 
from fiber-diffraction measurements (the $\mathrm{A}^{-}, \mathrm{B}^{-}, \mathrm{B}^{\prime-}, \mathrm{C}^{-}$, and $\mathrm{D}-\mathrm{hel}-$ ices), theoretical minimum-energy forms, and variants of the first two categories generated by thermal fluctuations in tilt and twist. The intensity at $275 \mathrm{~nm}$ was most strongly correlated with winding angle and twist. All the parameters, except step height, were found to be linked. Thus, earlier interpretations of CD premelting in terms of decreased winding angle are probably oversimplified in terms of the conformational change that is actually occurring.

Some authors have suggested a connection between premelting changes in helical structure and temperature effects on hydration of nucleic acid polymers. It has been reported ${ }^{11}$ that the slope of the premelting intensity increase at $276 \mathrm{~nm}$ in DNA shows a strong positive correlation with the heat of hydration of the solvent cation $\left(\mathrm{Li}^{+}\right.$ $>\mathrm{Na}^{+}>\mathrm{K}^{+}>\mathrm{NH}_{4}$ ). The authors propose that temperature-dependent changes in the hydration of cations bound to or near DNA phosphates affect the backbone conformation. Similar factors are invoked by DeMurcia et al. ${ }^{6}$ to explain the reduction in $T_{m}$ and CD premelting changes in the presence of tetramethylammonium (TMA ${ }^{+}$) ions, which are less hydrated than alkaline cations. However, these authors must also include a specific binding of TMA+ to A:T pairs as part of their hypothesis.

Is it possible to apply the results and conclusions from CD-premelting studies of DNA to our observations on RNA double helices? In DNA and poly[d(A-T)], the positive long-wavelength band increases with temperature, while in $\mathrm{AU}$, it decreases (Ref. 30 and this work-Figs. 8 and 10) and in IC remains constant (Fig. 9). In IC, there is a shorterwavelength positive band which does decrease in the premelt (Figs. 9 and 10). Double-stranded RNAs are prevented, by the bulk of the 2'$\mathrm{OH}$ group, from assuming the $\mathrm{B}$ - or C-helix. ${ }^{31}$ The structure that agrees best with diffraction measurements, RNA-11, has 11 base pairs per turn, as does A-DNA. Another possible model is RNA-10, with the same winding angle as B-DNA, but with a tilt closer to that of ADNA. ${ }^{31}$ In DNA, the intensity of the long-wavelength positive band decreases from the A family, characterized by a smaller winding angle (larger number of base pairs per turn), larger twist angle, and negative tilt, to the B family ${ }^{15}$ By analogy, AU and IC may show a decrease in $\mathrm{CD}$ intensity in the premelt due to a transition between a conformation similar to RNA-11, and one closer to RNA-10, exhibiting a larger winding angle and a less negative tilt. It is interesting to note that the same sort of temperature dependence described for the DNA positive band is displayed by the negative band at shorter wavelengths (244-247 nm) in AU (Figs. 8 and 10). The interpretation of premelting in this band, like the analogous band in DNA, is rather unclear. ${ }^{15}$

In contrast to the opposite trends seen in the premelting region, the long-wavelength positive bands in both DNA ${ }^{5-8,10}$ and RNA (Ref. 30 and this work-see Figs. 8-10) decrease in the helix-coil transition. 
In each case, the band also experiences a red shift upon melting. The fact that these trends are common to DNA and RNA is consistent with the view that the cooperative denaturation of both types of double helices is, at least qualitatively, similar.

\section{Comparison of Spectroscopic Premelting with HX-Detected Opening}

Premelting changes in the Raman spectrum of $\mathrm{AU}^{12}$ and calf-thymus DNA, ${ }^{13,14}$ are generally in the same direction; that is, increasing or decreasing intensity, red-or blueshift, as the corresponding changes during melting. We have found this same pattern in most of our ir data, with the notable exception of the $1505 \mathrm{~cm}^{-1}$ band in IC (Fig. 6). With DNA, the similarity in trends between premelting and melting contrasts with the trend reversal observed in CD spectra. Premelting changes in the Raman bands appear to be caused by partial unstacking and hydrogen-bond breakage. Since these processes continue during cooperative denaturation, it is not surprising that the spectral changes are in the same direction, but larger in magnitude. On the other hand, premelting effects observed by $\mathrm{CD}$ have been attributed to small changes in the winding angle and associated helical parameters. Since the collapse of the ordered structure upon denaturation involves both unstacking of bases and hydrogen-bond breakage, there is no reason to predict a spectral effect in the same direction as premelting. According to this view, it may be a coincidence of unrelated factors that results in CD melting-intensity changes in the same direction in RNA, but in different directions in DNA.

The CD premelting data for IC could support an interpretation different from the one based on DNA studies. Unlike the component polyribonucleotides in $\mathrm{AU}$, poly $(\mathrm{rI})$ and poly $(\mathrm{rC})$ have markedly different CD spectra. ${ }^{32}$ Comparing these to the spectrum of IC leads to the tentative assignment, in the latter (see Fig. 9), of the positive band at $244 \mathrm{~nm}$ to hypoxanthine-hypoxanthine stacking interactions, and the positive band at $277 \mathrm{~nm}$ to cytosine-cytosine stacking. Poly(rI) forms a quadruple-helical complex in high salt at low temperatures. ${ }^{33}$ The premelting decrease in the $244 \mathrm{~nm}$ band (Fig. 10) might then reflect an opening of regions in the double helix and exposure of inosinic residues to the solvent, followed by intramolecular complex formation and disruption at higher temperatures. According to this hypothesis, the lack of premelting change in the 277-nm band would be due to the inability of cytidylic residues to associate.

There are several difficulties that arise from the hypothesis just presented. It has been argued previously that any low-temperature base-pair opening detected by our methods must occur in very short units. It may not be possible for isolated open inosinic residues to form a complex. Also, if $\mathrm{CD}$ is sensitive to the small amount of opening in 
IC ( $1 \%$ from $\mathrm{HX}$ measurements), one might expect the $277-\mathrm{nm}$ band to change as exposed cytosines unstack. Both hypoxanthine and cytosine vibrational bands in the ir spectrum do show premelting changes consistent with unstacking.

It has been suggested that the ir spectral effects observed in the premelting region are related to some sort of localized disruption of the native structure. If ir is monitoring base-pairing opening, then the enthalpy associated with changes in the vibrational bands should be equal to the enthalpy derived from HX measurements. However, the average $\Delta H^{0}$ calculated from the ir data is about three times larger than any of the values determined from HX in both AU and IC (Table V). It is improbable that another frequent mode of opening could exist undetected by HX measurements. ${ }^{17}$ Therefore, a more likely conclusion is that ir measurements are hardly affected by the open state detected by $\mathrm{HX}$, but rather are dominated by a set of other conformational changes that do not cause exchange of protons although they determine the enthalpy of the ir premelting transition.

For example, a minimal model proposed for the open state in AU involves a swinging out of the uracil base while keeping the adenine stacked. ${ }^{17}$ An alternative model, postulating motile solitons, now seems less likely in view of recent $\mathrm{HX}$ data on oligonucleotides. ${ }^{34}$ Ir might monitor these perturbations in some small way, but will still be determined by other deformations that involve, for example, unstacking of the adenine, and further excursions of the uracil, which do not effect any (additional) HX.

While the averages of the enthalpies obtained from ir measurements are quite similar for the two synthetic RNAs, CD spectroscopy yields a much larger $H^{0}$ in IC than in $\mathrm{AU}$ (Table V). The greater temperature dependence of the short-wavelength positive band in IC (both measurements listed in Table $\mathrm{V}$ are derived from that band-see Table IV) may reflect a conformation change of a character different from the transition measured by $\mathrm{CD}$ in $\mathrm{AU}$. The fact that the enthalpy for $\mathrm{CD}$ premelting in IC approaches the average value from ir measurements is consistent with the alternate hypothesis previously discussed. On the other hand, it is possible that the same process could produce spectral effects of a different magnitude in the two synthetic RNAs, just as uv hyperchromicity is sequence-dependent.

Small changes in winding angle and other helical parameters have been invoked to explain CD premelting in DNA, and this hypothesis is perhaps applicable to the RNA data, as well. This type of conformational effect would be expected to involve a smaller enthalpy than base-pair opening, provided that the units participating in each process are equal in size. But Table $\mathrm{V}$ shows a slightly larger average enthalpy for $\mathrm{CD}$, compared to $\mathrm{HX}$, measurements in $\mathrm{AU}$. The average $\Delta H^{\circ}$ values for $\mathrm{CD}$ premelting in $\mathrm{AU}$ fall within the range of literature estimates from data on poly[d(A-T).$^{5,7}$ It is possible, then, that $\mathrm{CD}$ 
monitors a change in winding angle, twist, etc., involving relatively large stretches of nucleotides, but which is insensitive to the opening of isolated base pairs.

These tentative conclusions on the relationship between premelting phenomena detected by $\mathrm{HX}$, ir, and CD can be tested by further investigations with different polymers and different conditions of salt and $\mathrm{pH}$. These studies are in progress.

This research was supported by Grants CA 31207 and GM 29272 from the NIH, and NSF Grant PCM 0-04043.

\section{References}

1. Poland, D. \& Scheraga, H. A. (1970) Theory of Helix-Coil Transitions in Biopolymers, Academic, New York.

2. Fritzsche, H. (1982) Comm. Mol. Cell. Biophys. 1, 325-336.

3. Palacek, E. (1976) Prog. Nucl. Acid Res. Mol. Biol. 18, 151-213.

4. Bezdekova, A. \& Palacek, E. (1972) Stud. Biophys. (Berl.) 34, 141-149.

5. Brahms, S., Brahms, J. \& Van Holde, K. E. (1976) Proc. Natl. Acad. Sci. USA 73, 3453-3457.

6. De Murcia, G., Wilhelm, B., Wilhelm, F. S. \& Daune, M. P. (1978) Biophys. Chem. 8, 377-383.

7. Gennis, R. B. \& Cantor, C. R. (1972) J. Mol. Biol. 65, 381-399.

8. Greve, J., Maestre, M. F. \& Levin, A. (1977) Biopolymers 16, 1489-1504.

9. Sarocchi, M.-T. \& Guschlbauer, W. (1973) Eur. J. Biochem. 34, 232-240.

10. Sprecher, C. A. \& Johnson Jr., W. C. (1982) Biopolymers 21, 321-329.

11. Studdert, D. S., Patroni, M. \& Davis, R. C. (1972) Biopolymers 11, 761-779.

12. Small, E. W. \& Peticolas, W. L. (1971) Biopolymers 10, 1377-1416.

13. Erfurth, S. C. \& Peticolas, W. L. (1975) Biopolymers 14, 247-264.

14. Rimai, L., Maher, V. M., Gill, D., Salmeen, I. \& McCormick, J. J. (1974) Biochim. Biophys. Acta 361, 155-165.

15. Johnson, B. B., Dahl, K. S., Tinoco, Jr., I., Ivanov, V. I. \& Zhurkin, V. B. (1981) Biochemistry 20, 73-78.

16. Preisler, R. S., Mandal, C., Englander, S. W., Kallenbach, N. R., Howard, F. B., Frazier, J. \& Miles, H. T. (1981) in Biomolecular Stereodynamics I, Sarma, R. H., Ed., Adenine, New York, pp. 405-415.

17. Mandal, D., Kallenbach, N. R. \& Englander, S. W. (1979) J. Mol. Biol. 135, 391411.

18. Miles, H. T. (1971) in Procedures in Nucleic Acid Research, Vol, 2, Cantoni, G. L. \& Davies, D. R., Eds., Harper and Row, New York, pp. 205-232.

19. Powell, J. 'T., Richards, E. G. \& Gratzer, W. B. (1972) Biopolymers 11, 235-250.

20. Englander, J. J., Kallenbach, N. R. \& Englander, S. W. (1972) J. Mol. Biol. 63, 153-169.

21. Wang, A. C. \& Kallenbach, N. R. (1971) J. Mol. Biol. 62, 591-611.

22. Nakanishi, M. \& Tsuboi, M. (1978) J. Mol. Biol. 124, 61-71.

23. Miles, H. T. (1961) Proc. Natl. Acad. Sci. USA 47, 791-802.

24. Szybalski, E. H. \& Szybalski, W. (1975) in Handbook of Biochemistry and Molecular Biology, 3rd ed., Nucleic Acids, Vol I, Fasman, G. D., Ed., Chemical Rubber Co., Cleveland, pp. $575-588$.

25. Stevens, C. L. \& Felsenfeld, G. (1964) Biopolymers 2, 293-314.

26. Gralla, J. \& Crothers, D. M. (1973) J. Mol. Biol. 78, 301-319.

27. Miles, H. T. (1975) in Handbook of Biochemistry and Molecular Biology, 3rd ed., Nucleic Acids, Vol. I, Fasman, G. D., Ed., Chemical Rubber Co., Cleveland, pp. 604-623. 
28. Wang, J. C. (1969) J. Mol. Biol. 43, 25-39.

29. Zimmerman, S. B. \& Pheiffer, B. H. (1980) J. Mol. Biol. 142, 315-330.

30. Hashizume, H. \& Imahori, K. (1967) J. Biochem. 61, 738-749.

31. Cantor, C. R. \& Schimmel, P. R. (1980) Biophysical Chemistry, Part I-The Conformation of Biological Macromolecules, W. H. Freeman and Co., San Francisco, pp. 183184.

32. Borer, P. N. (1975) Handbook of Biochemistry and Molecular Biology, 3rd ed., Nucleic Acids, Vol I, Fasman, G. D., Ed., Chemical Co., Cleveland, pp. 592-594.

33. Miles, H. T. \& Frazier, J. (1978) J. Am. Chem. Soc. 100, 8037-8038.

34. Englander, S. W. \& Kallenback, N. P., (1984) Q. Rev. Biophys. 16, 521-655.

Received August 10, 1983

Accepted February 29, 84 